\title{
Oxygen Inhibition of Oscillations in the Belousov-Zhabotinsky Reaction
}

\author{
Oliver Steinbock,* Chad T. Hamik, and Bettina Steinbock \\ Department of Chemistry, Florida State University, Tallahassee, Florida 32306-4390
}

Received: February 10, 2000; In Final Form: April 25, 2000

\begin{abstract}
The inhibitory effect of molecular oxygen on chemical oscillations in a semiclosed Belousov-Zhabotinsky system is investigated. Comparison of experimental results obtained from anaerobic and aerobic reactions shows that the oxygen-induced increase of oscillation periods is most pronounced at low concentrations of sulfuric acid or bromate and at high concentrations of malonic acid. Under the given experimental conditions, oxygen inhibition is negligible for $\left[\mathrm{H}_{2} \mathrm{SO}_{4}\right]>0.35 \mathrm{M},\left[\mathrm{BrO}_{3}{ }^{-}\right]>0.15 \mathrm{M}$, and $\left[\mathrm{CH}_{2}(\mathrm{COOH})_{2}\right]<0.07 \mathrm{M}$. Based on the classical Oregonator, we propose an extended model that accounts for the observed concentration dependencies. This model treats oxygen as a dynamic variable and is capable of describing oxygen oscillations as well as the striking increase in oxygen concentration for conditions in which oscillations are fully suppressed. The rate equations of the extended Oregonator model are presented in a dimensionless form and are, for anaerobic conditions, in exact correspondence to the classical model.
\end{abstract}

\section{Introduction}

Molecular oxygen gives rise to distinct changes in the dynamic behavior of the Belousov-Zhabotinsky (BZ) reaction that affect chemical oscillations as well as wave propagation in this system. ${ }^{1-6}$ The inhibitory effect of oxygen has already been reported shortly after the development of the Field-KörösNoyes (FKN) mechanism ${ }^{7}$ and confirmed the assumption of a free-radical mechanism. ${ }^{8}$ A decreasing sensitivity of the BZ reaction toward oxygen with increasing acidity was discussed. Only little quantitative and sometimes contradicting data on the effects of oxygen have become available in the following years. ${ }^{9-11}$ However, the study of oxygen effects has recently regained considerable interest. These efforts were driven by the observation of interesting phenomena associated with the presence of oxygen such as complex oscillations ${ }^{1}$ and unusual modes of pattern formation. ${ }^{12}$ Furthermore, using the inhibitory effect of oxygen, three-dimensional wave patterns such as scroll waves have been obtained in a controlled fashion. ${ }^{13}$ These results underline the potential of oxygen as an externally applied control parameter for the study of temporal as well as spatiotemporal self-organization in the $\mathrm{BZ}$ reaction.

Extended Oregonator models have been put forward to describe the various oxygen effects. Krug et al ${ }^{14}$ introduced an additional, unspecified reaction that produces the inhibitor bromide with a fixed rate. Consequently the effect of oxygen is constantly applied throughout the different phases of an oscillatory cycle. Zhabotinsky et al. ${ }^{12}$ specifically modified the stoichiometric factor of the bromide production in the Oregonator model and Taylor et al. ${ }^{15}$ adjusted the effective rate of the reduction of the catalyst to model their experimental results. Wang et al. ${ }^{1}$ increased the value of two effective rate constants, which are crucial for the release of bromide in the organic subset of their model. None of these models attempt to introduce oxygen as a dynamic variable. Rather the effects of an oxygen altered mechanism are mimicked by a change of some effective rate of bromide release. However, modeling temporal and spatiotemporal oxygen profiles is of immediate interest since the oxygen concentration is experimentally accessible through specific oxygen sensors. Consequently, the presented work was undertaken to develop a model based on the Oregonator that treats oxygen as a dynamic variable rather than considering oxygen inhibition in a purely phenomenological fashion. Our study aims to efficiently incorporate the essence of recent advances regarding the mechanism of the organic subset of the BZ reaction. ${ }^{16-18}$ These include, for instance, the identification of the peroxymalonyl radical and the investigation of the structure of branching pathways in the aerobic oxidation of malonic acid by cerium(IV).

\section{A. Reaction Mechanism}

The reaction model to be described is based on the wellknown Oregonator model ${ }^{19,20}$ of the BZ reaction. The Oregonator is frequently used to simulate the dynamic behavior of the BZ system and has been successfully employed for modeling a broad variety of temporal and spatiotemporal phenomena. ${ }^{22-25}$ In contrast to the Brusselator ${ }^{26}$ and other generic models, ${ }^{27}$ the Oregonator is based on a chemically justified, but simplified, basis of the reaction processes in the BZ system.

The Oregonator model involves six major species for which we will use the following notation: $\mathrm{A}=\mathrm{BrO}_{3}{ }^{-}, \mathrm{B}=$ organic acids, $\mathrm{P}=\mathrm{HOBr}, \mathrm{U}=\mathrm{HBrO}_{2}, \mathrm{~V}=$ catalyst (oxidized), and $\mathrm{W}$ $=\mathrm{Br}^{-}$. The variable $\mathrm{B}$ is considered to be the sum of malonic acid and bromomalonic acid (these species are not distinguished in the framework of the Oregonator model).

The kinetic changes in the concentration of the above species are determined by five irreversible reactions:

$$
\begin{gathered}
\mathrm{A}+\mathrm{W} \rightarrow \mathrm{U}+\mathrm{P} \\
\mathrm{U}+\mathrm{W} \rightarrow 2 \mathrm{P} \\
\mathrm{A}+\mathrm{U} \rightarrow 2 \mathrm{U}+2 \mathrm{~V} \\
2 \mathrm{U} \rightarrow \mathrm{A}+\mathrm{P} \\
\mathrm{B}+\mathrm{V} \rightarrow h \mathrm{~W}
\end{gathered}
$$

The corresponding rate constants $k_{1}$ through $k_{5}$ have been extensively studied in the earlier literature..$^{28-32}$ The stoichiometric coefficient $h$ is a crucial bifurcation parameter of the system. Its value (typically between 0.5 and 2 ) is determined by complex organic oxidation reactions that give rise to an

\subsection{1/jp000531+ CCC: $\$ 19.00 \quad$ C 2000 American Chemical Society}

Published on Web 06/16/2000 
increase in bromide concentration. Typically, the concentrations of $\mathrm{A}$ and $\mathrm{B}$ are considered constant since bromate and the organic acids are present in large excess.

Free radicals produced as intermediates in reaction $\mathrm{r} 5$ are the key species for oxygen effects in the BZ reaction. A simplified picture of the corresponding reaction channels is given by the following mechanism:

$$
\begin{gathered}
\mathrm{B}+\mathrm{V} \rightarrow \mathrm{R} \\
2 \mathrm{R} \rightarrow 2 h \mathrm{~W} \\
\mathrm{R}+\mathrm{I} \rightarrow \mathrm{Q} \\
2 \mathrm{Q} \rightarrow 2 h^{\prime} \mathrm{W}+n \mathrm{I}
\end{gathered}
$$

in which $\mathrm{R}, \mathrm{Q}$, and I denote the malonyl/bromomalonyl radical, the corresponding peroxyl radicals, and molecular oxygen, respectively. In the following, the rate constants of these four irreversible reactions are denoted as $k_{5 \mathrm{a}}$ to $k_{8}$, respectively.

The structure of the above mechanism is branched in the sense that the primary radical $\mathrm{R}$ can either undergo a second-order self-decay (reaction 6) or react with oxygen to form a peroxyl radical (reaction 7). The parameters $h$ and $h^{\prime}$ are stoichiometric coefficients, which determine the amount of bromide produced via the anaerobic (reactions 5a and 6) and the oxygen-specific reaction pathway (reactions 5a, 7, and 8), respectively. Notice, that reactions $\mathrm{r} 7$ and $\mathrm{r} 8$ have no relevance under strictly anaerobic conditions. The constant $n$ is the stoichiometric coefficient of oxygen in the fast recombination reaction of peroxyl radicals. The numeric value of $n$ is expected to be either zero or one, since $n=2$ would imply that oxygen is not consumed in the overall reaction.

A noteworthy feature of the reaction mechanism (reactions $5 a-8)$ is that it matches the reaction ( $r 5)$ of the Oregonator, if the oxygen concentration is zero and if reaction $\mathrm{r} 5 \mathrm{a}$ is the ratedetermining step along the reaction pathway (reactions 5a and 6). If one assumes that reaction 5a is the rate-limiting step, one can conclude that the rate constant $k_{5 \mathrm{a}}$ equals the rate constant $k_{5}$ of the classical Oregonator.

\section{B. Rate Equations}

Based on the reaction mechanism (reactions 1-4, 5a, 6-8), rate laws that describe the temporal evolution of the concentration of $\mathrm{U}, \mathrm{V}, \mathrm{W}, \mathrm{I}, \mathrm{R}$, and $\mathrm{Q}$ can be derived. The concentrations of $\mathrm{A}$ and $\mathrm{B}$ are considered constant.

$$
\begin{gathered}
\mathrm{d}[\mathrm{U}] / \mathrm{dt}=k_{1}[\mathrm{~A}][\mathrm{W}]-k_{2}[\mathrm{U}][\mathrm{W}]+k_{3}[\mathrm{~A}][\mathrm{U}]-2 k_{4}[\mathrm{U}]^{2} \\
\mathrm{~d}[\mathrm{~V}] / \mathrm{d} t=2 k_{3}[\mathrm{~A}][\mathrm{U}]-k_{5}[\mathrm{~B}][\mathrm{V}] \\
\mathrm{d}[\mathrm{W}] / \mathrm{d} t=-k_{1}[\mathrm{~A}][\mathrm{W}]-k_{2}[\mathrm{U}][\mathrm{W}]+2 h k_{6}[\mathrm{R}]^{2}+2 h^{\prime} k_{8}[\mathrm{Q}]^{2} \\
\mathrm{~d}[\mathrm{I}] / \mathrm{d} t=-k_{7}[\mathrm{R}][\mathrm{I}]+n k_{8}[\mathrm{Q}]^{2} \\
\mathrm{~d}[\mathrm{R}] / \mathrm{d} t=k_{5}[\mathrm{~B}][\mathrm{V}]-2 k_{6}[\mathrm{R}]^{2}-k_{7}[\mathrm{R}][\mathrm{I}] \\
\mathrm{d}[\mathrm{Q}] / \mathrm{d} t=k_{7}[\mathrm{R}][\mathrm{I}]-2 k_{8}[\mathrm{Q}]^{2}
\end{gathered}
$$

Steady-state approximations are applied to the variables $\mathrm{R}$ and $\mathrm{Q}$, since the decay reactions of the organic radicals are known to be fast.

$$
\mathrm{d}[\mathrm{Q}] / \mathrm{d} t=0 \Longrightarrow[\mathrm{Q}]_{\mathrm{ss}}=\left\{\left(k_{7}[\mathrm{R}][\mathrm{I}]\right) /\left(2 k_{8}\right)\right\}^{1 / 2}
$$

$$
\begin{aligned}
\mathrm{d}[\mathrm{R}] / \mathrm{d} t=0 \Longrightarrow[\mathrm{R}]_{\mathrm{ss}}=\left(4 k_{6}\right)^{-1}\left\{\left(\left(k_{7}[\mathrm{I}]\right)^{2}+\right.\right. \\
\\
\left.\left.\quad 8 k_{5} k_{6}[\mathrm{~B}][\mathrm{V}]\right)^{1 / 2}-k_{7}[\mathrm{I}]\right\}
\end{aligned}
$$

This approximation yields a set of four differential equations that describe the temporal evolution of the reaction system. It consists of the unmodified equations (eqs 1a,b) and the rate laws for bromide and oxygen (eqs 1c,d) in which [R] and [Q] are replaced by the corresponding steady-state concentrations.

\section{C. Dimensionless Equations}

It is useful to transform this set of rate equations into a dimensionless form. For this purpose, the following variables are introduced:

$$
\begin{gathered}
u=\left(2 k_{4}\right) /\left(k_{3}[\mathrm{~A}]\right)[\mathrm{U}] \\
v=\left(k_{4} k_{5}[\mathrm{~B}]\right) /\left(k_{3}[\mathrm{~A}]\right)^{2}[\mathrm{~V}] \\
w=k_{2} /\left(k_{3}[\mathrm{~A}]\right)[\mathrm{W}] \\
i=\left(k_{4} /\left(32 k_{6}\right)\right)^{1 / 2} k_{7} /\left(k_{3}[\mathrm{~A}]\right)[\mathrm{I}] \\
t=k_{5}[\mathrm{~B}] \times \text { time }
\end{gathered}
$$

and complemented by a set of additional parameters:

$$
\begin{gathered}
\epsilon=\left(k_{5}[\mathrm{~B}]\right) /\left(k_{3}[\mathrm{~A}]\right) \\
\epsilon^{\prime}=\left(2 k_{4} k_{5}[\mathrm{~B}]\right) /\left(k_{2} k_{3}[\mathrm{~A}]\right) \\
\epsilon^{\prime \prime}=\left\{k_{5}[\mathrm{~B}]\left(2 k_{4} k_{6}\right)^{1 / 2}\right\} /\left\{k_{3} k_{7}[\mathrm{~A}](2-n)\right\} \\
q=\left(2 k_{1} k_{4}\right) /\left(k_{2} k_{3}\right) \\
f=2 h \\
f^{\prime}=2 h^{\prime} \\
\sigma=\left(\epsilon^{\prime \prime} k_{\mathrm{fl}}\right) /\left(k_{5}[\mathrm{~B}]\right)
\end{gathered}
$$

The parameter $k_{\mathrm{fl}}$ in eq $5 \mathrm{~g}$ is the rate of oxygen inflow into the reaction system. For example, this inflow of the inhibitor could arise from stirring of a batch system, diffusive transport of oxygen from the gas phase into a shallow BZ layer, or continuous purging of the system with an oxygen-containing gas. The parameter $\sigma$ in the form given by eq $5 \mathrm{~g}$ is appropriate if the oxygen inflow can be modeled by a rate $\mathrm{d}[\mathrm{I}] / \mathrm{d} t$ that equals $k_{\mathrm{fl}}\left([\mathrm{I}]_{\mathrm{s}}-[\mathrm{I}]\right)$, with $[\mathrm{I}]_{\mathrm{s}}$ being the saturation concentration of oxygen under the given experimental conditions.

The transformations of variables and the definitions of parameters given above allow the reformulation of the rate laws for $u, v, w$, and $i$ that were obtained under the steadyapproximations (eqs 2a,b):

$$
\begin{gathered}
\epsilon \mathrm{d} u / \mathrm{d} t=q w-u w+u-u^{2} \\
\mathrm{~d} v / \mathrm{d} t=u-v \\
\epsilon^{\prime} \mathrm{d} w / \mathrm{d} t=-q w-u w+4 f \chi^{2}+8 f^{\prime} i \chi \\
\epsilon^{\prime \prime} \mathrm{d} i / \mathrm{d} t=-i \chi
\end{gathered}
$$

where $\chi=\left\{\left(i^{2}+v / 4\right)^{1 / 2}-i\right\}$.

In the complete absence of oxygen (i.e., $i \equiv 0$ ) the value of $\chi^{2}$ equals $v / 4$ and eqs $6 \mathrm{a}-\mathrm{d}$ match the classical Oregonator 
model. In particular, we find the rate terms in eq $6 \mathrm{c}$ turn into the familiar expression $-q w-u w+f v$.

\section{D. Rate constants}

The numerical values of the parameters of eqs $6 a-d$ require the knowledge of the concentrations of A (bromate) and B (malonic acid), the flow rate of oxygen, the stoichiometries $h$, $h^{\prime}$, and $n$, and seven rate constants. The values of $\mathrm{A}$ and $\mathrm{B}$ are typically known, while $h$ and $h^{\prime}$ will be treated as the empirical parameters. This approach is similar to the treatment of $h$ in the classical Oregonator model. The value of the stoichiometric coefficient $n$ is assumed to be one.

The rate constants $k_{1}$ to $k_{5}$ are identical to the corresponding rate constants of the unmodified Oregonator. Several sets have been proposed in the earlier literature, including Tyson and Keener's "Lo" and "Hi" values ${ }^{20}$ and data obtained from thorough mechanistic studies by Field and Försterling ${ }^{29}$ and Försterling and Stuck. ${ }^{29,30}$ In this study, we employed the following set of rate constants:

$$
\begin{gathered}
k_{1}=2.0 \mathrm{M}^{-3} \mathrm{~s}^{-1}\left[\mathrm{H}^{+}\right]^{2} ; \quad k_{2}=1.0 \times 10^{6} \mathrm{M}^{-2} \mathrm{~s}^{-1}\left[\mathrm{H}^{+}\right] ; \\
k_{3}=40.0 \mathrm{M}^{-2} \mathrm{~s}^{-1}\left[\mathrm{H}^{+}\right] \\
k_{4}=2.0 \times 10^{3} \mathrm{M}^{-1} \mathrm{~s}^{-1} ; \quad k_{5}=0.3 \mathrm{M}^{-1} \mathrm{~s}^{-1}
\end{gathered}
$$

which are Tyson and Keener's "Lo" values except for the value $k_{5}$, which was taken from recent references. ${ }^{30}$

The rate constant, $k_{6}$, of the second-order self-decay of the malonyl radicals has been measured in EPR experiments. Försterling and Stuck $^{30}$ found this rate constant to be $k_{6}=4.2$ $\times 10^{8} \mathrm{M}^{-1} \mathrm{~s}^{-1}$ for a $1 \mathrm{M}$ sulfuric acid solution at room temperature. An estimate for the rate constant, $k_{7}$, of the recombination reaction of the peroxylmalonyl radical has been given by Neumann et al. ${ }^{17}$ These authors performed stoppedflow EPR measurements of the aerobic oxidation of malonic acid in $1 \mathrm{M}$ sulfuric acid. The observed decay kinetics of the peroxyl radical yielded a rate constant of $k_{7}=1.7 \times 10^{7} \mathrm{M}^{-1}$ $\mathrm{s}^{-1}$ in the framework of a seven-step autoxidation mechanism.

The study by Neumann et al. ${ }^{17}$ also yielded an estimated value of $2.2 \times 10^{8} \mathrm{M}^{-1} \mathrm{~s}^{-1}$ for the rate constant $k_{8}$. Notice that exact knowledge of the numeric value of $k_{8}$ is not explicitly required by eqs $6 \mathrm{a}-\mathrm{d}$ since $k_{8}$ is eliminated by the steady-state assumption $\mathrm{d}[\mathrm{Q}] / \mathrm{d} t=0$. However, the numeric value $k_{8}=2.2 \times 10^{8}$ $\mathrm{M}^{-1} \mathrm{~s}^{-1}$ was used for comparing numerical results obtained from eqs $6 \mathrm{a}-\mathrm{d}$ and eqs $1 \mathrm{a}-\mathrm{f}$. This comparison revealed very good agreement.

\section{Experimental Section}

All experiments on oxygen-induced inhibition of chemical oscillations were performed by using a UV/vis diode-array spectrophotometer (Hewlett-Packard, HP8453). Measurements were carried out at $25.0 \pm 0.5^{\circ}$. The oscillation periods were obtained for various sets of initial concentrations by monitoring the absorption evolution of Ce(IV) at a wavelength of $390 \mathrm{~nm}$. During the course of the reaction, the system was purged with either nitrogen or oxygen. All chemicals were of the highest grade commercially available and used without further purification. While the initial concentrations of malonic acid (Fisher), bromate (Fisher), and sulfuric acid (Fisher) were varied systematically, the reaction was always initiated by adding a small volume of $\mathrm{Ce}\left(\mathrm{NH}_{4}\right)_{4}\left(\mathrm{SO}_{4}\right)_{4} \cdot 2 \mathrm{H}_{2} \mathrm{O}$ (initial concentration: $[\mathrm{Ce}(\mathrm{IV})]=0.95 \mathrm{mM})$.

\section{Results}

4a.Oscillation and Relaxation of the Oxygen Concentration. In 1996 Wang et al. ${ }^{1}$ reported experimental results that
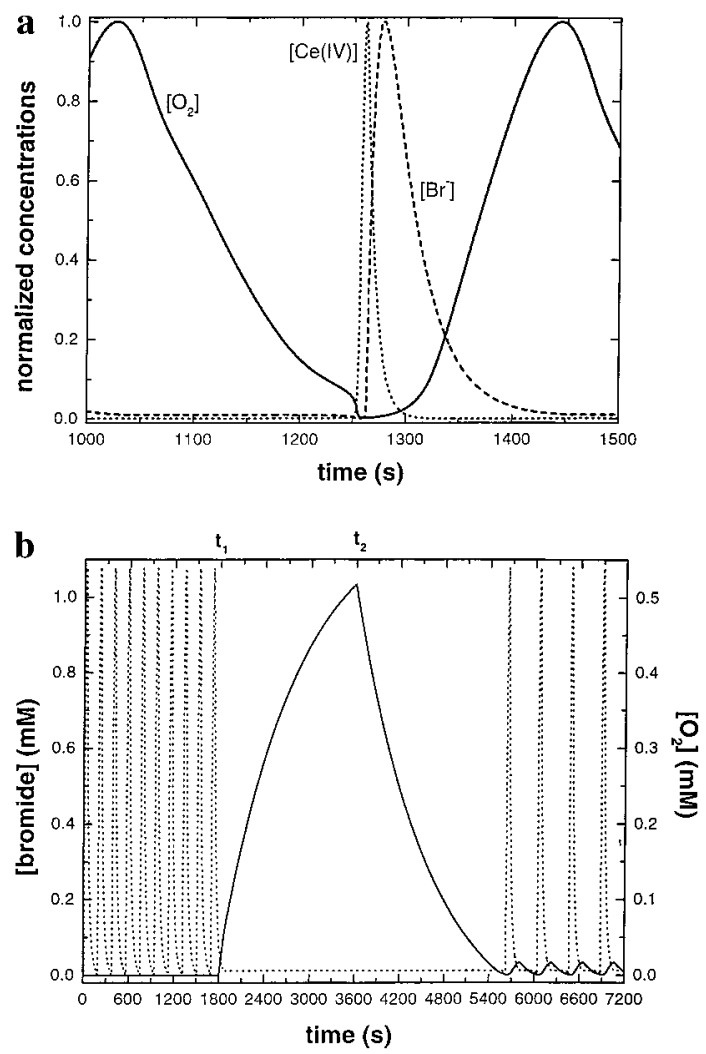

Figure 1. (a) Temporal evolution of the normalized concentrations of oxygen, $\mathrm{Ce}(\mathrm{IV})$, and bromide calculated by using the modified Oregonator model (reactions $\mathrm{r} 1-\mathrm{r} 4, \mathrm{r} 5 \mathrm{a}, \mathrm{r} 6-\mathrm{r} 8$ ). Parameters: $\mathrm{A}=0.2$ $\mathrm{M}, \mathrm{B}=0.4 \mathrm{M}, \mathrm{H}=0.2 \mathrm{M}, I_{\mathrm{s}}=0.3 \times 10^{-3} \mathrm{M}, n=1, f=1.0, f^{\prime}=$ 2.0 , and $k_{\mathrm{fl}}=1 \times 10^{-3} \mathrm{~s}^{-1}$. (b) Response of the system to changes in the flow rate of oxygen. Dashed and solid lines represent the concentrations of bromide and oxygen, respectively.

revealed small-amplitude oscillations of oxygen concentration in semiclosed BZ systems. Their investigation focused on wellstirred systems that are closed except for transport of oxygen from the atmosphere across a free surface. The inflow rate of oxygen was controlled by varying the stirring rate, which resulted in transfer rates in the order of $k_{\mathrm{fl}}=0.1$ to $0.2 \mathrm{~min}^{-1}$ (i.e., approximately $1.0 \times 10^{-3} \mathrm{~s}^{-1}$ ). One particular finding of their study is that an increase in flow rate can lead to the suppression of chemical oscillations. This inhibition of oscillations triggers a remarkable change in the oxygen kinetics: a change occurs from low-amplitude oscillations to a regime in which the concentration increases monotonically and eventually saturates at a value more than 10 times higher.

Furthermore, the experiments by Wang et al. ${ }^{1}$ reveal a characteristic phase relation between the oscillating concentrations of Ce(IV) and oxygen. The phase of the oscillations during which the $\mathrm{Ce}(\mathrm{IV})$ concentration is low corresponds to an increasing concentration of oxygen, while the fast increase in $\mathrm{Ce}(\mathrm{IV})$ during the autocatalytic production of $\mathrm{HBrO}_{2}$ corresponds to a rapid decrease in oxygen concentration.

These major experimental findings were used to perform qualitative tests of the modified Oregonator model (reactions $1-4,5 a, 6-8)$. All numerical simulations were carried out by Euler integration of eqs $6 \mathrm{a}-\mathrm{d}$. In all calculations the integration time step was $\Delta t=1.0 \times 10^{-6}$. Figure 1a shows a typical example of the evolution of the normalized concentrations of oxygen, $\mathrm{Ce}(\mathrm{IV})$, and bromide. Because of the interplay of constant oxygen inflow and reaction-induced oxygen consumption, the oxygen concentration is found to oscillate with the period of the other chemical species. The phase dependence 
between the different oscillating species, however, reveals interesting details. Our calculations show that oxygen is at its lowest concentration level when most of the cerium ions are oxidized $(t=1250-1300 \mathrm{~s}$ in Figure 1a). This phase is followed by a relatively smooth increase in oxygen concentration (13001450 s). Consequently, the oscillations of oxygen and Ce(IV) have a phase difference of nearly $180^{\circ}$ in this model. Notice that the time at which the rate of oxygen consumption reaches a maximum $(1250 \mathrm{~s})$ correlates to the instance in which the autocatalysis of $\mathrm{HBrO}_{2}$ sets in and the $\mathrm{Ce}(\mathrm{IV})$ concentration rapidly increases. This finding seems reasonable in the framework of our initial reaction mechanism since the concentration of the malonyl radical is strongly correlated to $\mathrm{Ce}$ (IV).

Figure $1 \mathrm{~b}$ illustrates the behavior of the system with respect to changes in the flow rate, $k_{\mathrm{fl}}$, of oxygen. The dashed line in Figure $1 \mathrm{~b}$ represents the dynamics of the bromide concentration, while the oxygen concentration is plotted as a solid line. Initially the oxygen concentration of the reservoir, $i_{\mathrm{a}}$, is zero. Under these strictly anaerobic conditions, the variables $u, v$, and $w$ oscillate according to the classical Oregonator model, while the value of $i$ equals 0 . At the time $t_{1}=1800 \mathrm{~s}$, the dimensionless parameter $i_{\mathrm{A}}$ is increased from zero to the value that corresponds to the saturation concentration of $1 \mathrm{mM}$ oxygen. This parameter jump inhibits the oscillations immediately and the bromide concentration remains constant at a low level. The oxygen concentration, however, increases significantly in a monotonic fashion. At time $t_{2}(3600 \mathrm{~s})$ the saturation concentration of oxygen is decreased to $0.3 \mathrm{mM}$. The initial response of the system is a continuous decrease of oxygen concentration. At approximately $t=5600 \mathrm{~s}$ the oxygen concentration has decayed to a level that allows the onset of oscillations. However, the oscillation period is longer than the period under anaerobic conditions and the variable, $i$, shows small-amplitude oscillations.

4b. Concentration Dependence of Oxygen Inhibition. Experimental Results. The comparison of experimental and numerical data on the dependence between the strength of the inhibition and the concentrations of $\mathrm{A}, \mathrm{B}$, and $\mathrm{H}$ constitutes an important test of the presented model. Figure 2a shows an example for the influence of molecular oxygen on the oscillation period, $T$, of a $\mathrm{Ce}(\mathrm{IV})$-catalyzed $\mathrm{BZ}$ system as a function of the sulfuric acid concentration. Open circles and solid circles represent measurements under anaerobic and aerobic conditions, respectively. The small inset shows the same data in terms of the period ratio $T\left(\mathrm{O}_{2}\right): T\left(\mathrm{~N}_{2}\right)$. The periods were calculated by averaging the duration of the first six oscillation cycles. At high concentrations of sulfuric acid no significant differences in the oscillation period of the aerobic and the anaerobic reactions are found. At low concentrations, however, the periods differ by a factor of up to 3 with longer periods found in the presence of oxygen. Under the given experimental conditions, the sensitivity of the $\mathrm{BZ}$ reaction to oxygen inhibition is therefore most pronounced at low acidity.

The concentration dependence of the oxygen inhibition on the initial concentrations of malonic acid and bromate is shown in Figure 2b,c. Similar to the data shown in Figure 2a, the effect of oxygen inhibition decreases with increasing concentration of bromate (Figure 2b). Under the given experimental conditions, the maximal increase of the oscillation period was approximately $40 \%$. The effect of malonic acid on oxygeninduced inhibition, however, revealed that inhibition is strong for high initial concentrations of the organic substrate (Figure 2c). On the basis of these experimental data, we conclude that
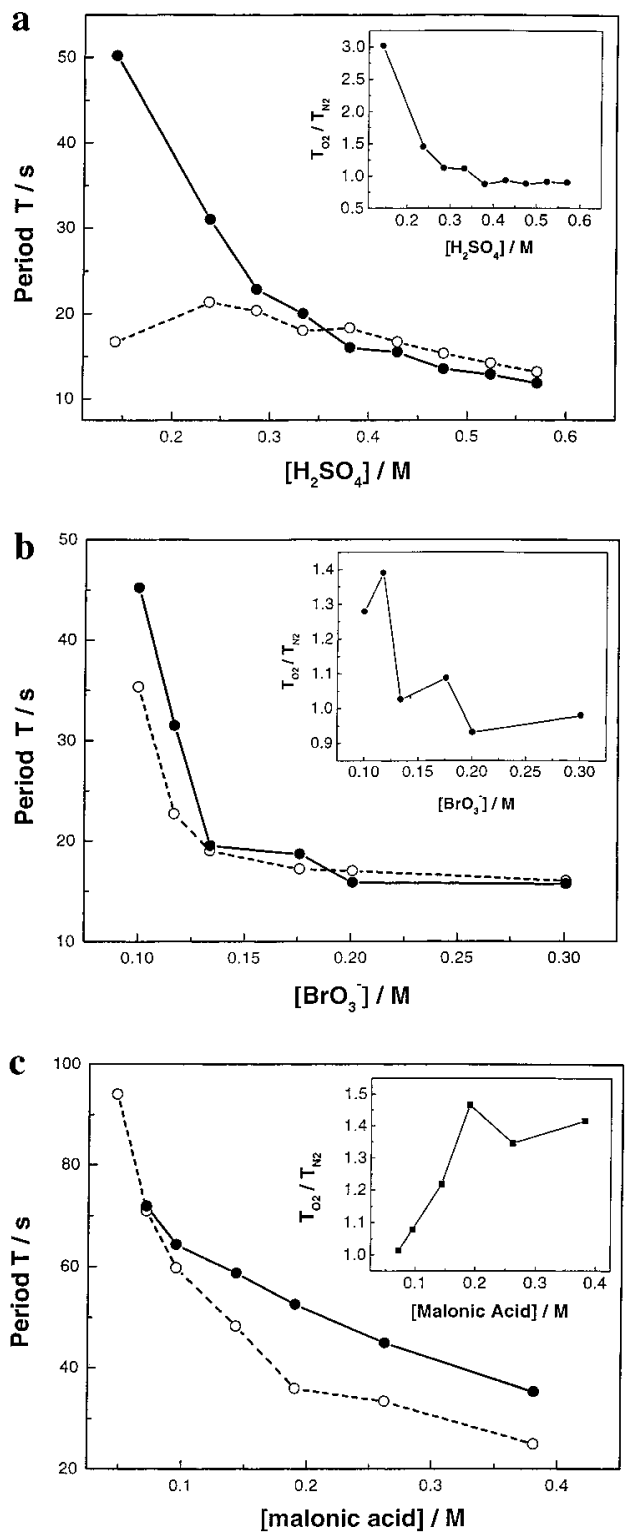

Figure 2. Oscillation periods as a function of initial concentrations. Open and solid circles represent data obtained from experiments in which the reaction solution was continuously purged with nitrogen and oxygen, respectively. The insets show the same data as the ratio of the periods for aerobic and anaerobic conditions. (a) $\left[\mathrm{NaBrO}_{3}\right]=0.17 \mathrm{M}$, $[$ malonic acid $]=0.95 \mathrm{M},\left[\mathrm{H}_{2} \mathrm{SO}_{4}\right]=0.14-0.57 \mathrm{M}$; (b) $\left[\mathrm{NaBrO}_{3}\right]=$ $0.1-0.3 \mathrm{M}$, [malonic acid] $=0.95 \mathrm{M},\left[\mathrm{H}_{2} \mathrm{SO}_{4}\right]=0.33 \mathrm{M}$; (c) $\left[\mathrm{NaBrO}_{3}\right]$ $=0.2 \mathrm{M}$, [malonic acid $]=0.048-0.37 \mathrm{M},\left[\mathrm{H}_{2} \mathrm{SO}_{4}\right]=0.33 \mathrm{M}$.

oxygen inhibition is negligible for $\left[\mathrm{H}_{2} \mathrm{SO}_{4}\right]>0.35 \mathrm{M},\left[\mathrm{BrO}_{3}{ }^{-}\right]$ $>0.15 \mathrm{M}$, and $\left[\mathrm{CH}_{2}(\mathrm{COOH})_{2}\right]<0.07 \mathrm{M}$.

Numerical Results. Figure $3 \mathrm{a}-\mathrm{c}$ shows the results obtained by numerical integration of eqs $6 \mathrm{a}-\mathrm{f}$ for initial concentrations $\mathrm{A}, \mathrm{B}$, and $\mathrm{H}$ that are close to the experimental ones of Figure $2 \mathrm{a}-\mathrm{c}$. All numerical simulations were carried out using the parameters $k_{\mathrm{fl}}=1.0 \times 10^{-3} \mathrm{~s}^{-1}, n=1.0, f=1.0, f^{\prime}=2.0$. No attempts have been undertaken to improve the quantitative agreement between experimental and numerical data by adjusting the numeric values of $f$ and $f^{\prime}$, since such efforts most likely would fail to yield a unique result that could be applied to various initial conditions. In this respect, the modified Oregonator model shares the weaknesses of the classical Oregonator.

The data shown in Figure 3 reveal systematic differences between the oscillation periods of the anaerobic $\left(\left[\mathrm{I}_{\mathrm{s}}\right]=0.0 \mathrm{mM}\right.$; dashed line) and the aerobic system $\left(\left[\mathrm{I}_{\mathrm{s}}\right]=1.0 \mathrm{mM}\right.$; solid line $)$. 

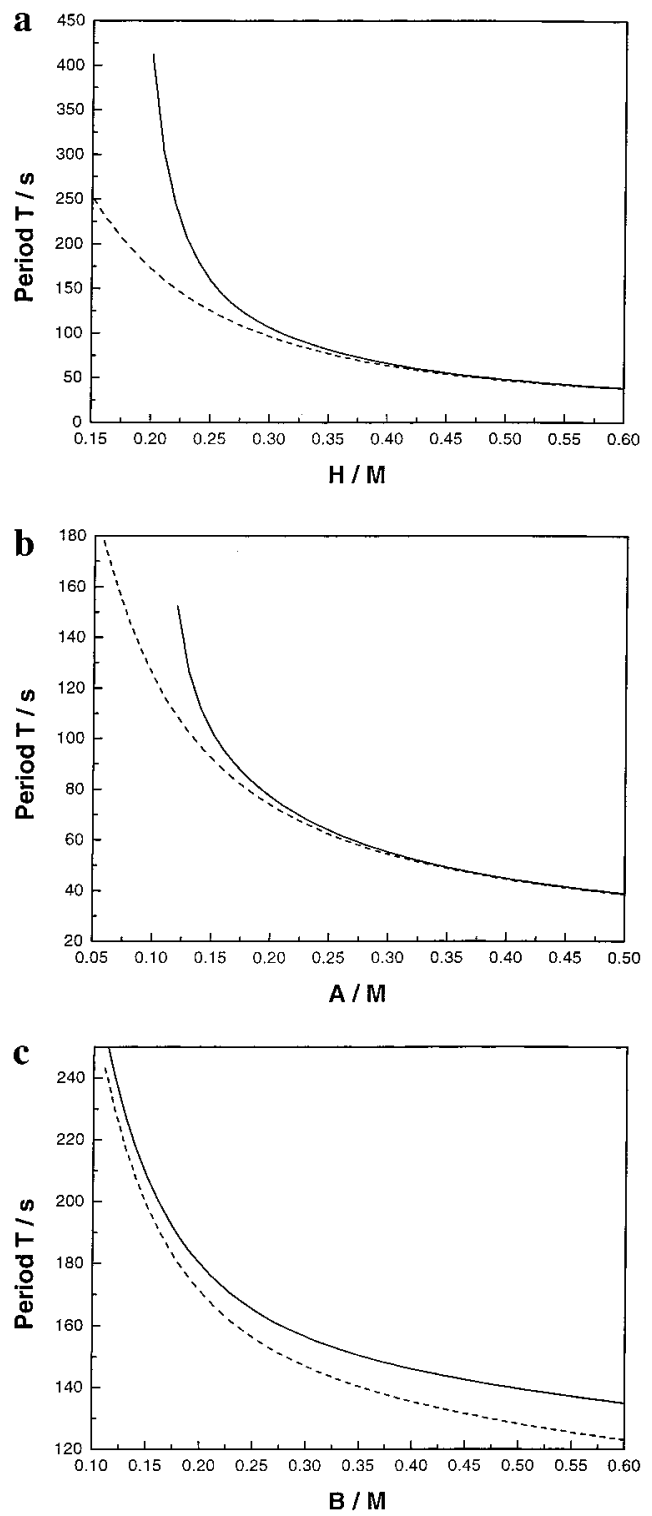

Figure 3. Oscillation periods as a function of initial concentrations obtained by numerical integration of eqs $6 \mathrm{a}-\mathrm{f}$. The dashed and the solid lines indicate results for $\left[\mathrm{O}_{2}\right]_{\mathrm{s}}=0.0$ and $1.0 \mathrm{mM}$, respectively. Parameters: (a) $\mathrm{A}=0.17 \mathrm{M}, \mathrm{B}=0.95 \mathrm{M}$; (b) $\mathrm{H}=0.33 \mathrm{M}, \mathrm{B}=0.2$ $\mathrm{M}$; (c) $\mathrm{A}=0.2 \mathrm{M}, \mathrm{H}=0.25 \mathrm{M}$. All other parameters were kept constant: $k_{\mathrm{fl}}=1 \times 10^{-3} \mathrm{~s}^{-1}, n=1.0, f=1.0$, and $f^{\prime}=2.0$.

These differences are most pronounced at low concentrations of sulfuric acid (a) and bromate (b) and at high concentrations of the organic substrate (c). The presented numeric results are, therefore, in good qualitative agreement with the experimental findings presented in Figure 3.

Additional results indicate that variations of the stoichiometric coefficient $n(0<n<2)$ cause no qualitative changes in the described concentration dependencies. The strength of oxygen inhibition, however, is larger for small values of $n$ since the consumption of oxygen is less efficient.

\section{Conclusions}

Based on the classical Oregonator model of the BelousovZhabotinsky reaction, an extended model has been described that accounts for the consumption of oxygen and its inhibitory effect on chemical oscillations in this reaction system. The extended model is capable of describing the occurrence of oxygen oscillations that have been observed earlier in experiments in which oxygen is continuously delivered to the system. Also the dramatic increase in the oxygen concentration that accompanies the oxygen-induced quenching of oscillations is reproduced properly. Another important feature of the presented model is that is successful in describing the qualitative dependence between oxygen-induced increases of oscillation periods and the concentrations of sulfuric acid, bromate, and malonic acid.

We are confident that the extended Oregonator will prove to be a useful model for the numerical analysis of oxygen-related effects in spatially extended systems. These applications could include investigations of wave profiles and velocities in thin layers of the BZ system as well as studies of wave phenomena in three-dimensional media.

Acknowledgment. We thank U. Storb for discussions. This work was supported by Florida State University.

\section{References and Notes}

(1) Wang, J.; Hynne, F.; Sørensen, P. G.; Nielsen, K. J. Phys. Chem. 1996, 100, 17593

(2) Ruoff, P.; Noyes, R. M. J. Phys. Chem. 1989, 93, 7394.

(3) Zhabotinsky, A. M.; Müller, S. C.; Hess, B. Chem. Phys. Lett. 1990, 172,445 .

(4) Hartenberger, U. Diploma Thesis, University of Dortmund, Germany, 1993.

(5) Steinbock, O.; Müller, S. C. J. Phys. Chem. A 1998, 102, 6485.

(6) Petrascu, A.-M.; Koch, M. H. J.; Försterling, H.-D. J. Phys. Chem A 1999, 103, 6757. 8649 .

(7) Field, R. J.; Körös, E.; Noyes, R. M. J. Am. Chem. Soc. 1972, 94

(8) Váradi, Z.; Beck, M. T. J. Chem. Soc. 1973, 30.

(9) Roux, J.-C.; Rossi A. C. R. Acad. Sc. Paris Ser. C 1978, 287, 151

(10) Bar-Eli, K.; Haddad, S. J. Phys. Chem. 1979, 83, 2953.

(11) Treindl, L.; Fabian, P. Collect. Czech. Chem. Commun. 1980, 45, 1168 .

(12) Zhabotinsky, A. M.; Györgyi, L.; Dolnik, M.; Epstein, I. R. J. Phys. Chem. 1994, 98, 7981.

(13) Taylor, A. F.; Johnson, B. R.; Scott, S. K. Phys. Chem. Chem. Phys. 1999, 1,807 . 4862 .

(14) Krug, H. J.; Pohlmann, L.; Kuhnert, L. J. Phys. Chem. 1990, 94,

(15) Taylor, A. F.; Gaspar, V.; Johnson, B. R.; Scott, S. K. Phys. Chem. Chem. Phys. 1999, $1,4595$.

(16) Gao, Y.; Försterling, H. D.; Noszticzius, Z.; Meyer, B. J. Phys. Chem. 1994, 98, 8377.

(17) Neumann, B.; Müller, S. C.; Hauser, M. J. B.; Steinbock, O.; Simoyi, R. H.; Dalal, N. S. J. Am. Chem. Soc. 1995, 117, 6372.

(18) Neumann, B.; Steinbock, O.; Müller, S. C.; Dalal, N. S. J. Phys. Chem. 1997, 101, 2743.

(19) Field, R. J.; Noyes, R. M. J. Chem. Phys. 1974, 60, 1877.

(20) Tyson, J. J.; Keener, J. P. Physica D 1988, 32, 327.

(21) Brazhnik, P. K.; Tyson, J. J. Phys. Rev. E 1999, 59, 3920.

(22) Taylor, A. F.; Johnson, B. R.; Scott, S. K. J. Chem. Soc., Faraday Trans. 1998, 94, 1029.

(23) Kettunen, P.; Amemiya, T.; Ohmori, T., Yamaguchi, T. Phys. Rev E 1999, 60, 1512

(24) Karma A.; Zykov, V. S. Phys. Rev. Lett. 1999, 83, 2453.

(25) Sevcicova, H.; Schreiber, I.; Marek, M. J. Phys. Chem. 1996, 100, 19153.

(26) Prigogine, I.; Lefever, R. J. Chem. Phys. 1968, 48, 1695.

(27) Barkley, D. Physica D 1991, 49, 61.

(28) Tyson, J. J. In Oscillations and Travelling waves in Chemical Systems; Field, R. J., Burger, M., Eds.; Wiley-Interscience: New York, 1985; p 93.

(29) Field, R. J.; Försterling, H. D. J. Phys. Chem. 1986, 90, 5400.

(30) Försterling, H. D.; Stuck, L. J. Phys. Chem. 1992, 96, 3067.

(31) Barkin, S.; Bixon, M.; Noyes, R. M.; Bar Eli, K. Int. J. Chem. Kinet. 1978, 10, 619 .

(32) Försterling, H. D.; Pachl, R.; Schreiber, H. Z. Naturforsch. 1987, $42 a, 963$. 